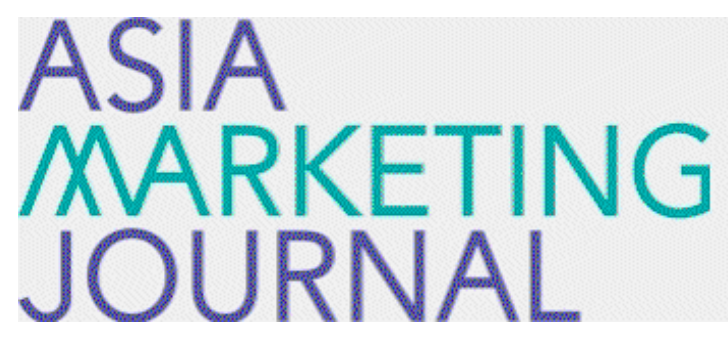

ASIA MARKETING JOURNAL

\title{
A Study on the Role of Locomotion Orientation as an Antecedent of Salespeople`Selling Behavior
}

Ihn Goo Lee

Seong Goo Ji

Follow this and additional works at: https://amj.kma.re.kr/journal

Part of the Marketing Commons

\section{Recommended Citation}

Lee, Ihn Goo and Ji, Seong Goo (2013) "A Study on the Role of Locomotion Orientation as an Antecedent of Salespeople`Selling Behavior," Asia Marketing Journal: Vol. 15 : Iss. 2 , Article 8.

Available at: https://doi.org/10.53728/2765-6500.1523

This Article is brought to you for free and open access by Asia Marketing Journal. It has been accepted for inclusion in Asia Marketing Journal by an authorized editor of Asia Marketing Journal. 


\title{
A Study on the Role of Locomotion Orientation as an Antecedent of Salespeople' Selling Behavior
}

\author{
Ihn Goo Lee* \\ Seong Goo Ji**
}

The purpose of this study is to investigate the effects of the locomotion orientation on salespeople sales performance with the mediating effect of selling behavior(adaptive selling behavior, SOCO). And we figure out the relationship between customer-oriented selling behavior and adaptive selling behavior because those relationships are not clear. The authors infer research hypotheses based on literature review.

We have confirmed the reliability and validity test and those results can be acceptable. Hypotheses test were conducted with structural equation modeling. AMOS. All paths in the research model reasoned by authors have been supported statistically at the significant level.

This study with the theoretical implications is as follows. First, this study is the first attempt to investigate the path between locomotion orientation and adaptive selling behavior and SOCO. Secondly, there is an empirical conflict between our study and Franke and Park(2006)'s study. Our study was contradictory to Franke and Park(2006)'s consequences. And so, figuring out clearly those causal paths remains.

This study with practical implications are as follows.

First of all, the salespeople selling performance was affected by adaptive selling behavior, customeroriented selling behavior, and sales-oriented activities, such as the importance of selling behavior once again proven. It is necessary to enhance the capabilities that can be transformed into action appropriate to the needs of customers each sales step-by-step in the process of salespeople for various system through education and incentives, and to interact with customers and understand their customers relative to salespeople will. In order to enhance adaptive selling behavior, the company needs to do educational program and monitoring system with the positional promotion when salespeople get the high adaptive selling behavior.

Secondly, the locomotion orientation of the salespeople is to cause this selling behavior. Management style to increase locomotion orientation is needed, which means, salespeople superior about something should be conducted. In order to stimulate the selling behavior of the salespeople, most supervisors should use some managerial tools such as feedback, engagement, and rewards.

Key words: locomotion orientation, adaptive selling behavior, customer-oriented selling behavior, sales-oriented selling behavior, sales performance

\footnotetext{
* Ph, D, Dept. of Business Administration, Marketing Division, Kumho Tire Co.. Ltd.

** Associate Professor. Dept. of Business \& Accounting. Hanbat National University(sgji@hanbat.ac.kr), corresponding author
} 


\section{Introduction}

Selling performance of salespeople who sell products and service is an important variable to explain corporate performance as it is directly related to business revenue. Antecedent variables that affect their selling performance positively include working smart, working hard (Sujan, Weitz, and Kumar, 1994), adaptive selling, customer-oriented selling(Franke and Park, 2006: Yoo et al., 2008), working relationship quality (Park and Deitz, 2006). Antecedents that affect selling performance can be classified into behavioral aspects, relational aspects, and organizational management aspects.

Sales performance of salespeople can be best explained by behavioral aspects. In studies on selling behavior, adaptive selling behavior and sales orientation - customer orientation (SOCO) are the two most important constructs. Interaction with customers or adaptive selling behavior which is understood as to change selling behavior in customer interaction(Weitz, Sujan, and Sujan, 1986) and customer-oriented selling behavior which is recognized as to implement a marketing concept at the individual level of salespeople' selling behavior(Saxe and Weitz, 1982) are the key of selling behavior studies among others.

To being with, constructs with adaptive selling behavior and causal relationship include learning orientation(Yoo et al., 2008), adaptive behavior pattern by customer type(Kim et al., 2009), intrinsic motivation(Roman and Iacobucci, 2010), sales experience(Franke and Park, 2006). relationship quality(Park and Deitz, 2006), and the study on variables related to customeroriented selling behaviors include job satisfaction (Cravens et al., 1993), customer value-oriented culture(Flaherty, Dahlstrom, and Skinner, 1999), selling skills(Wachner, Plouffe, and Gregorie, 2009) and relational selling strategy(Guenzi, Pardo, and Georges, 2007). Many studies were conducted on salespeople's selling behavior which lead to sales performance. But, few studies on motivational factor for behavior were made, especially not based on recent and state-theof-art theories. And we need to develop new approach to selling behavior.

Except Franke and Park's meta analysis (2006), there were few previous studies that dealt with adaptive selling behavior and SOCO, the two pillars of a selling behavior were studied under one model. In other words, it is necessary to deal with adaptive selling behavior and SOCO under one integrated model. It is important to recognize salespeople's selling behaviors in an integrated framework because it helps us to understand causal relationships between selling behaviors, relative importances among those sales-related variables, and more usages of practical implications. The view of integrated approach can lead us to have some multidimensional thoughts on sales behaviors which seem to be very complicated. This study 
proposes 'motivational factor $\rightarrow$ selling behavior $\rightarrow$ sales performance as an integrated framework to explain the causal relationship of antecedents and consequences of selling behavior in order to draw theoretical and managerial implications.

Especially, researchers of this study have developed a theory model focusing on motivational factors with which selling behavior at an individual level can be explained. In a study of sales management, it is important to deal with salespeople's individual characteristics and the role of a motivational factor in a research should be known(Weitz, Sujan, and Sujan, 1986). Sociopsychological approach is being addressed in a recent study on the motivational factor leading to selling behavior derived as a self regulatory mode, locomotion orientation and assessment orientation(Kruglanski et al., 2000).

Locomotion and assessment orientation is not a continuum but independent. Self-regulation can explain how salespeople will act, be oriented, and be focused by motivational change. In case of explaining selling behavior of salespeople who are oriented to make changes responding to their customers, locomotion orientation is to be a better variable for it. Locomotion orientation guides attention, resources, and action to achieve goals by dealing with changes (Jasmand et al., 2012). It's related to goal pursuit. Adaptive selling behavior, customeroriented selling behavior, and sales-oriented selling behavior needs lots of changes in behavior of salespeople.
In other words, because adaptive selling behavior and SOCO need to be changeable in conditions of sales environment, locomotion orientation better than assessment orientation is to be suitable for explaining causal relationships between motivational factor and selling behavior. And so, we adopt the only locomotion orientation that can be motivational factor for sales behavior. Jasmand et al.(2012) introduced this concept to selling behavior research in which locomotion orientation affects ambidextrous behavior.

This self regulatory mode for its effect on adaptive selling behavior and SOCO verifies that it seems to contribute to theory on the abundance of salespeople motivational factor affecting managerial dimension of the variable determine what the practical implications were looking for.

Therefore, the purpose of this study, first of all, is to investigate the effects of the locomotion orientation on salespeople's selling performance with the mediating effect of selling behavior. Second, we were to figure out the relationship between customer-oriented selling behavior and adaptive selling behavior because those relationships are not clear. There are some conflicts in empirical results between them.

The differentiation of this study from other existing model is that this research empirically tired to investigate causal paths between a self regulatory mode and adaptive selling behavior and SOCO. This study is the only research which has dealt with locomotion orientation 
and those selling behaviors.

\section{Theoretical Background and Research Model}

\subsection{Theoretical Background}

Salespeople's selling performance is affected by selling behavior at the level of individual salespeople directly to corporate sales volume. Many of the existing studies discuss the causal relationship to the salespeople selling performance, but this study based on the integrated framework of 'motivational factor $\rightarrow$ selling behavior $\rightarrow$ sales performance' was carried out.

\subsubsection{Selling behavior}

Adaptive selling behavior and SOCO on selling behavior has mainly been addressed in the research construct. The construct of adaptive selling behavior on the theoretical research studies has been done since the late 1960s in the United States. Walker et al.(1977) in the field of industrial psychology scholars have provided the first and theoretical foundation for it. It was introduced to the field in earnest sales field by Weitz(1979) (Kim et al., 2009). According to the definition of Weitz et al. (1986), "The practice of adaptive selling is defined as the altering of sales behaviors during a customer interaction or across customer interactions based on perceived information about the nature of the selling situation" is defined.

Spiro and Weitz(1990)'S study of the ADAPTS measured by further development of the initial concept of adaptive selling behavior has been developed. ADAPTS scale consists of three components, the first, motivation for salespeople's intention to act, second, ability required to take an action of adaptive selling behavior, third, the salespeople's actual adaptive behavior. Most of the research view of adaptive selling behavior addressed as a single- dimensional adaptive selling behavior(Roman and Iacobucci, 2010). On the sales process, in most of the conceptual model of the feedback, the loops and the form of the interaction between selling behavior and sales subjects color that explicitly mentions(Spiro and Weitz, 1990), most of the studies dealing with a single dimension can be seen to be consistent with measurement theory that emphasizes unidimensionality.

Effect of adaptive selling behavior is to bring lasting relationships with customers and is to exceed benefits of offsetting the cost of obtaining information of customers and reacting to customers. And it brings the lower conflict in the relationship between customers(Franke and Park, 2006). In most of the research on adaptive selling behavior, adaptive selling behavior as a mediator variable has a positive effect on personal and organizational performance, and from a different perspective, studies 
were investigated about antecedents of adaptive selling behavior. By the type of achievement type, egoistic type, relational type, separated by the type of customers, sales persuasion tactics appropriate for each type(Information Exchange, Recommendation, Promise, Threats, Ingratiation, Inspirational Appeal) by presented Kim et al. (2009)'s study showed that the height of other persuasion tactics for each type straightened purchase satisfaction. Gwinner et al.(2005) identify antecedents of interpersonal adaptive behavior and service offering adaptive behavior, the customer knowledge and modifying self- presentation of the common affected and intrinsic motivation in significant service offering adaptive behavior appeared to be affecting.

In the meta analysis of adaptive selling behavior, the sales experience influenced adaptive selling behavior and adaptive selling behavior affected self-rated, manager-rated, and objective performance. It will give a positive impact on job satisfaction. Understanding of customers and customer classification as a sub-dimension of customer orientation was empirically tested to affect adaptive selling behavior(Yoo et al., 2008). Adaptive behavior as well as the mainstream of salespeople's selling behavior, which could be Sales Orientation Customer Orientation(SOCO), means that customersoriented selling behavior based on the marketing concept at the level of individual salespeople selling behavior and sales-oriented sell- ing behavior is the attempt to maximize shortterm sales to stimulate demand(Saxe and Weitz. 1982). Customers-oriented salespeople avoid actions that can cause many dissatisfied customers of behaviors and increase satisfaction for long-term customers(Schwepker, 2003).

Saxe and Weitz(1982)'s 24 SOCO measurement items were developed, most of the subsequent research in the selling orientation and customer orientation as a two-dimensional separated SOCO study model has been studied. SOCO model to reflect the entire research and marketing perspective can be divided into. Homburg, Muller, and Klarmann(2011)'s study showed that the relationship between salepeople's customers-orientation and sales performance was the non-linear curve of the relationship rather than linear relationship that said. It represented inverse U-shaped curve, which means that the existence of the optimal level of customer-orientation and performance could be.

In a study of the relationship between adaptive selling behavior and customer-oriented selling behavior, the meta analysis results said that adaptive selling behavior affected customeroriented selling, but customer-oriented selling's path to adaptive selling behavior was not observed(Franke and Park, 2006). This study is the only research that dealt with adaptive selling behavior and customer-oriented selling behavior in an integrated framework. And adaptive behavior and customer-oriented behavior 
positively affected performance, the variable of gender and experience were positive antecedents of adaptive selling behavior and customer-oriented behavior(Franke and Park, 2006). After this research, it is hard to see those constructs in an integrated framework.

\subsubsection{Locomotion Orientation}

People generally have two types of self-regulating tendency to, which is what people really want, and a person wants to get what he needs to evaluate what can be(Pierro et al., 2006). People have two functions which consist of the locomotion orientation and assessment orientation.

Locomotion orientation is that locomotion constitutes the aspect of self-regulation concerned with from state to state and committing the psychological resources that will initiate and maintain goal-related movement in a straightforward and direct manner, without undue distractions or delays. Assessment orientation is that assessment constitutes the comparative aspect of self-regulation concerned with critically evaluating entities or states, such as goals or means, in relation to alternatives in order to judge relative quality(Higgins and Kruglanski, 1995).

According to the theory of traditional control that aims to minimize the mismatch between the desired state and the current state, it may be that the purpose of the self-regulating will coordinate those functions. In order to achieve these objectives, the current state and a desired final state are compared. Self-regulation is involved in the evaluation function to work as a means to satisfy the goal(Pierro et al., 2006). Locomotion orientation and assessment orientation is an entity with a different phase. In a traditional control theory in that locomotion orientation and assessment orientation function cannot be separated from each other, two orientations generally have been treated as two self-regulating tendencies mutually interdependent (Kruglanski et al. 2000). Studies since this perspective, self-regulating, but generally anything that looks different opinion. Two self-regulating tendency of locomotion orientation and assessment orientation is orthogonal to each other (Kruglanski et al., 2000). In a viewpoint of relations of each other, the two concepts are not in the extremes of the continuum.

Locomotion-oriented people have a tendency to enjoy something and prefer to start the task on and the next step of the task of fast-moving efforts rather than critically to evaluate against any target(Jasmand et al., 2012), locomotion-oriented people by intrinsic motivation to take action, rather than the means of these behaviors tend to accept the purpose(Higgins et al., 2003). Locomotion-oriented people feel that they are more intrinsic rewards and higher perception that something is moving(Avent and Higgins, 2003).

Evaluation-oriented people prefer a critical 
assessment in order to determine the relative value of alternative status, means, and purpose. In addition, evaluation-oriented people prefer to wait and evaluate for all possible choices of any action before deciding(Jasmand et al., 2012). Intrinsic task motivation is positively related to the locomotion orientation whereas assessment orientation is related to extrinsic motivation (Pierro et al., 2006). Locomotion-oriented tendency tends to successfully change management and positive association(Kruglanski et al., 2007). According to the self-regulating tendency molded seats for service due to the failure to experience negative attribution research (Sung and Han, 2010). Evaluation-oriented customers more strong propensity regret bigger rather than goal-oriented inclination strong. In contrast, locomotion-oriented strong inclination customers showed a greater disappointment.

Self-regulatory mode approach can be a theoretical foundation for not consumer buying behavior but also salespeople selling behavior. For the first time in explaining salespeople behavior, Jasmand et al.(2012)'s study adopt the concept of self-regulatory tendency to salespeople's behavior. This study showed that locomotion orientation has a positive effect on ambidextrous behavior by the moderating effect of assessment orientation. And ambidextrous behavior has a positive effect on performance.

In this study, ambidextrous selling behavior refers to both service provision and cross-/upselling during service encounters(Jasmand et al., 2012). This theoretical approach is based on the concept of exploitation and exploration which is rooted in strategic management field. A positive effect of locomotion orientation on ambidextrous behavior becomes considerably enhanced when assessment orientation is high(Jasmand et al.. 2012). This means that these two orientations jointly affected selling behavior.

\subsection{Research Model and Hypotheses}

Research framework was used in this study on the basis of "locomotion orientation $\rightarrow$ selling behavior (adaptive selling behavior, SOCO) $\rightarrow$ sales performance' as a study model.

Salespeople behavior can explained by motivational factor and there were a few studies focusing on those issues(Roman and Iacobucci, 2010: Yoo et al., 2008). In recent years, the self regulatory mode has been in the theoretical mainstream of explaining behavior. The first research that dealt with self regulatory mode was Jasmand(2012)'s study. In his study, locomotion orientation had a positive effect on ambidextrous behavior and assessment orientation played as a role of mediating variable, not important (Jasmand et al., 2012). The key variable in a study of self regulatory mode has been known to be locomotion orientation.

People in high locomotion orientation tend to elicit a positive experience of change. Goaloriented people who want to challenge for the new experience select a new goal that is al- 
ways in motion, the elements essential motivation necessary for locomotion orientation by positive emotions, optimism, self respect, sense of self effectiveness and intrinsic motivation, because they are characterized(Kruglanski et al., 2007). In addition, functional requirements are different from human relations that are involved in the act of an individual's perceived competence. Competence is defined as flexibility, goal-oriented, performance which plays an important role in explaining the relationship between the selling behaviors(Sujan et al., 1994). Both adaptive selling behavior and SOCO seem to require some changes of salespeople behavior, and we think that locomotion orientation can be a variable for explaining sales behavior.

Yoo et al.(2008)'s study of adaptive selling and customer-oriented selling showed that selling behavior has a positive impact on sales ex- perience of salespeople(Franke and Park, 2006). Salespeople's intrinsic motivation to influence the salespeople's adaptive behavior has a positive impact on the performance of salespeople (Roman and Iacobucci, 2010), the multidimensional construct of adaptive behavior was studied also. To try new things in order to achieve the goal, and to adapt to changing series of selling behavior to have a positive impact on their salespeople's high locomotion orientation that can be inferred. In addition, the importance of customer-orientation in the success of a behavior control system(Cravens et al, 1993), customer-oriented culture and sales' customer-oriented selling behavior between positive relationships(Flaherty et al., 1999). Relational selling strategy gives a positive impact on customeroriented selling (Guenzi et al., 2007). Therefore, the following hypothesis is set.

\section{〈Figure 1〉 Research Model}

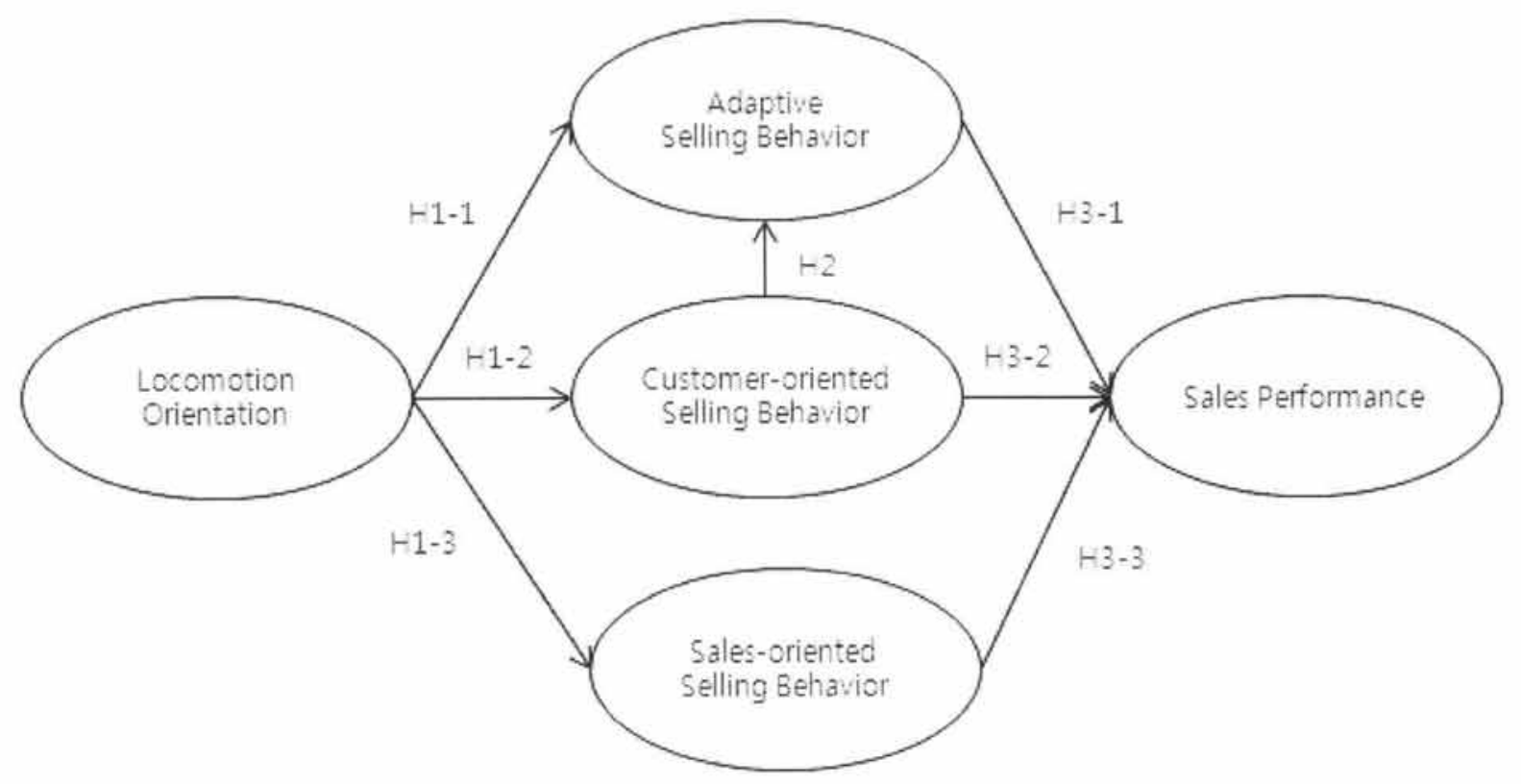

182 ASIA MARKETING JOURNAL Vol. 15 №. 02 July 2013 
H1-1: Locomotion orientation has a positive effect on adaptive selling behavior of salespeople.

H1-2: Locomotion orientation has a positive effect on customer-oriented selling behavior of salespeople.

H1-3: Locomotion orientation has a positive effect on sales-oriented selling behavior of salespeople.

The causal relationship between adaptive selling behavior and customer-oriented selling behavior has been controversial(Siguaw, 1991: Spiro and Weitz, 1990). And so, Franke and Park(2006)'s meta analysis made a clear notion that adaptive selling behavior has a positive effect on customer-oriented selling behavior. Customeroriented selling behavior to adaptive selling behavior was not significant. But, Roman and Iacobucci(2010)'s study showed different results that firm's customer orientation has a positive relationship with adaptive selling confidence. And so, the authors tried to make a clear causality of two constructs between adaptive behavior and customer-oriented behavior. We proposed this hypothesis like this.

\section{H2: Customer-oriented selling behavior has} a positive effect on adaptive selling behavior of salespeople.

In a study on the Korean automobile industry, performance and job satisfaction was mediated by relationship quality and adaptive selling behavior(Park and Deitz, 2006). Intrinsic motivation's effects on salespeople's adaptive selling behavior(Roman and Iacobucci, 2010), adaptive selling behavior on self-rated, manager-rated objective performance, positive impact on job satisfaction(Franke and Park, 2006), relationship mediated quality affects performance and job satisfaction(Park and Deitz, 2006). The relationship between customer orientation and salespeople' performance is positively correlated (Saxe and Weitz, 1982), and customer orientation has the impact on performance(Franke and Park, 2006: Martin and Bush, 2006), and job satisfaction is also positive(Craven et al., 1993: Siguaw et al., 1994). Salespeople's customer orientation positively affect satisfaction with salespeople and satisfaction with dealer gives satisfaction with salespeople selling orientation (Goff et al., 1997). Sales orientation and customer orientation, and selling skills affects performance(Wachner et al., 2009). Thus, higher sales representatives's adaptive selling behavior. bigger performance consistent findings are emerging. Thus, the following hypothesis is presented in this study.

H3-1: Adaptive selling behavior of salespeople has a positive effect on sales performance.

H3-2: Customer-oriented selling behavior of salespeople has a positive effect on sales performance. 
H3-3: Sales-oriented selling behavior of salespeople has a positive effect on sales performance.

\section{Methodology}

\subsection{Sample and Data Collection}

The sampling frame of this study is those who are working in the domestic service, wholesale/ retail, responsible for sales in the manufacturing. The authors collected data through an internet survey from a research company. The company holds the number of 800,000 panels. Data of this study were gathered from salespeople among panels. From July 4 to 8, 2012 panel data from this sample were collected through questionnaires. Some of screening questions were made and proper samples were finally selected.

The total number of reponses is above 1,000 answers, and we cut off about 700 responses which were not proper for this research. Excluding incomplete and biased responses, the authors obtained answers from 300 and a response rate is $35.1 \%$. And 300 data was used in the analysis. In the pre-study prior to this survey, we interviewed salespeople and so we revised contents of questionnaires after in-depth interview.

The questionnaire was composed of self-filling. The details of the configuration of the sample surveyed is as follows. Sampling data of this study showed that sex ratio configuration is composed of men $58.3 \%$ and women $41.7 \%$. industry includes the service industry distribution $63 \%$, wholesale/retail $25 \%$, finance and insurance $9.7 \%$, and manufacturing $2.3 \%$. Job position is composed of the employees $44.3 \%$, assistant and assistant manager 35\%, manager $13 \%$, general manager $4.7 \%$. Form B to B sales form is $20.3 \%$ and B to C sales is $79.7 \%$. A high school graduation is below $29 \%$, and above university graduation is $71 \%$. Data was collected from homogeneous groups and all responses are salespeople.

\subsection{Measures}

Multi-item measures of the construct was used in this study.

\subsubsection{Independent Variable}

Locomotion orientation is defined as 'from state to state and committing the psychological resources that will initiate and maintain goalrelated movement in a straightforward and direct manner: without undue distractions or delays'(Higgins and Kruglanski, 1995). 'When a specific job is to be done. I think the next task in mind', 'If I decide to do something, I start immediately.', 'My head that I want to achieve is the full.', 'I like to act rather than to view and observe., 'I have a tendency to deeply commit my jobs until those are to be done.' 'I 
don't hesitate to make additional efforts to wrap it up' items were measured(Kruglanski et al., 2000).

\subsubsection{Mediating Variables}

The practice of adaptive selling is defined as the altering of sales behaviors during a customer interaction or across customer interactions based on perceived information about the nature of the selling situation(Weitz et al., 1986). 'I am speaking style of a variety of sales, depending on the circumstances., 'I like that differentiated, try to get a different sales approach.' 'I am selling a variety of ways I can use., 'Customers request some different and unique ways of selling'. 'I use flexible ways of selling' were measured(Spiro and Weitz, 1990). SOCO is defined as follows.

Customer-oriented selling can be viewed as the practice of the marketing concept at the level of the individual salespeople and customer. Sales-oriented selling behavior means that there are actions that attempts to maximize shortterm sales gains by stimulating demand for products(Saxe and Weitz, 1982). Customer-oriented selling behavior 'I provide products(services) to help resolve the problems that customers have', 'I am trying to find out what can be beneficial to the customers in the products (services).', 'I provide a variety of information to the customers.', 'I try to answer the exact questions to customers.' Sales-oriented selling behavior. 'I try to focus on making sales rather than customer satisfaction:, "When I sell products to customers, it is necessary to distort the facts., 'In order to sell a product(service) to look good, I very positively expressed., 'I decide when to provide customers products(services), to give satisfaction to the customers in the short term, what I have to persuade customers to accept focuses'(Saxe and Weitz, 1982).

\subsubsection{Dependent Variable}

Sales performance was measured by asking each salespeople to rate his or her performance. It refers to relative evaluation of salespeople's performance(Oliver and Anderson, 1994: Homburg et al., 2011). 'As compared to other salespeople within the company and the performance of company's sales goals has contributed much to the evaluation?', 'Compared to other salespeople within the company and how your efforts evaluated?', 'Company how do you rate your overall sales performance in comparison with other sales representatives?', 'Your other sales representatives within the company's annual sales, compared with do you think about the location of any of the following that?', 'Compared with your competitors' sales, how do you rate representatives, compared with your customers secure fixed?', 'What about your customers' overall satisfaction level compared with competitors' sales representatives' would you rate the below average is not good, the average level 
of more than 4 points, and the average level of very good points were measured. Excluding sales performance, other variables were used by 7 point likert scale(1 - strongly not agree, 4-usually, 7-strongly agree) were measured.

\section{Results}

\subsection{Reliability and Validity Analysis}

Measurement validation procedure for the entire variable reliability and validity was analyzed in order. Reliability was analyzed using Cronbach's alpha. SPSS 14.0 was used for exploratory factor analysis and reliability analysis. The end of each variable reliability analysis, the final reliability results, locomotion orientation (.88), adaptive selling behavior(.88), customeroriented selling behavior $(.90)$, sales-oriented selling behavior(.82), sales performance(.90) to ensure reliability than .70(Nunnally, 1978). After the purification process, we did not use two measurement items of locomotion orientation.
At the reliability test, those two items lowered the reliability of locomotion orientation construct.

In this study, we conducted exploratory factor analysis to verify the validity. In order to determine the discriminant validity, a principal factor analysis was conducted. To maintain the mutual independence between factors, the varimax rotation approach as a method of factor rotation was conducted. Factor loading of .50 or better, cutting based on the eigen value of 1 was used.

An overview of factor analysis results is $70.04 \%$ in the cumulative variance, KaiserMeyer-Olkin value of .92, and compliance verification. The Bartlett sphericity validation is $4756.32, \mathrm{df}=276, p<.01$ which value is shown to be valid. Locomotion orientation factor loading's 61 to .75 , adaptive selling behavior factor loading's .58 to .77 , sales-oriented behavior's factor loading .74 to .83 , customer-oriented behavior's factor loading .72 to .80 , sales performance's factor loading .75 to .80 are shown in the above analysis, the entire variable discriminant validity was ensured. Especially. it is empirically proven to be different in con-

〈Table 1 CR \& AVE value

\begin{tabular}{|c|c|c|c|}
\hline Variable & Composite Reliability & AVE & $\begin{array}{c}\text { Standardized Factor } \\
\text { Loadings }\end{array}$ \\
\hline Locomotion Orientation & .89 & .58 & $.64 \sim .88$ \\
\hline Adaptive Selling Behavior & .89 & .61 & $.67 \sim .82$ \\
\hline Customer-oriented Selling Behavior & .91 & .72 & $.79 \sim .90$ \\
\hline Sales-oriented Selling Behavior & .83 & .54 & $.66 \sim .82$ \\
\hline Sales Performance & .91 & .67 & $.78 \sim .86$ \\
\hline
\end{tabular}


ceptual relationships between adaptive selling behavior and customer-oriented selling behavior.

In a confirmatory factor analysis, we again tested the reliability and convergent validity with composite reliability and AVE. At a glance of fitness indices, we found those values (Chi-square $=645.77, \mathrm{df}=243, p$-value $=.00, \mathrm{GFI}$ $=.86, \mathrm{RMSEA}=.07, \mathrm{CFI}=.91, \mathrm{PNFI}=.76$.). Composite reliability represented a internal consistency, and it's called construct reliability. The level that we can accept at is above the level of .7. Composite reliability of all variables is above .7, and the reliability was reaffirmed. And so, researchers can judge a convergent validity with another index of AVE. Generally, if AVE is above .5, the convergent validity can be accepted. All constructs in our study are above .5. In order to confirm a discriminant validity, we can empirically judge based on the rejection or acception of the hypothesis that constructs are same $(\mathrm{Phi}=0)$. In other words, we can infer that if the value of $\mathrm{Phi} \pm 2 \times \mathrm{S}$.E. is not 1 at the significant level of $95 \%$, there should be discriminant. At the results of this study, the value of $\mathrm{Phi} \pm 2 \times$ S.E. was not 1 , the discriminant validity was found.

And so, there can be a methodological problem with common method biases in this study because all variables of this research were measured from salespeople. In order to figure out these problems, the authors made Harman's one factor test(Podsakoff, MacKenzie, Lee and Podsakoff, 2003). In consequences of exploratory factor analysis for all variables of this research. we found five factors above the eigen value of ' 1 ' and the first factor can explain $22.72 \%$ of total variances. Based on these facts that five factors were induced and all were not explained by a certain factor, we can make a judgement that a methodological problem with common method biases is not critical.

\subsection{Descriptive Statistics and Correlations}

First, descriptive statistics and correlation analysis was conducted against the entire variable.

$\langle$ Table 2〉 Correlation Matrix

\begin{tabular}{|c|c|c|c|c|c|c|c|}
\hline & Mean & S.D. & LO & ASB & CO & SO & SP \\
\hline LO & 4.87 & .94 & 1 & & & & \\
\hline ASB & 4.68 & .94 & $.64^{* *}$ & 1 & & & \\
\hline CO & 5.10 & .96 & $.66^{* *}$ & $.66^{* *}$ & 1 & & \\
\hline SO & 4.20 & 1.08 & $.21^{* *}$ & $.33^{* *}$ & $.20^{* *}$ & 1 & \\
\hline SP & 4.66 & .84 & $.58^{* *}$ & $.61^{* *}$ & $.58^{* *}$ & $.28^{* *}$ & 1 \\
\hline
\end{tabular}

${ }^{* *} p<.01,{ }^{*} p<.05$

Note : $\mathrm{LO}=$ Locomotion Orientation, $\mathrm{ASB}=$ Adaptive Selling Behavior,

$\mathrm{CO}=$ Customer-oriented Selling Behavior, $\mathrm{SO}=$ Sales-oriented Selling Behavior,

$\mathrm{SP}=$ Sales Performance 
In analysis, appear relatively high, with 4.87 the average value of the locomotion orientation, salespeople's high locomotion orientation can be seen. Adaptive selling behavior, customeroriented behavior, and sales-oriented behavior, respectively 4.69, 5.10, 4.20, appeared customer orientation value most highly appeared, adaptive selling behavior. Appear as 4.66 finally, the sales performance salespeople to their own perception of performance and higher recognition were identified. Correlation relationship analysis, each variable was usually higher than the average, showed some degree of correlation relationship in variable.

Locomotion orientation which is an exogenous variable was related positively to selling behavior at the level of .01 and $.64, .66, .21$ correlation relationship. It is meaningfully consistent with the direction of the hypothesis. Secondly, the relationship between each of the selling behavior and sales performance adaptive selling behavior .61, customer-oriented selling behavior .58, sales-oriented selling behavior .28 value significant at the .01 level and hypothesis direction is consistent. Finally, the correlation value between customer-oriented selling behavior and adaptive selling behavior is .68 at the level of .01 which means there are to be a significant and implicational analysis needed.

We used AMOS structural equation modeling on how salespeople performance was affected. In the research model of this study presented, the better goodness of fit index gained through self-correction models has been proposed. As shown in 〈Figure 2〉, the goodness of fit indices were analyzed. The goodness of fit index of the first model of this $\operatorname{study}\left(\mathrm{x}^{2}=508.85\right.$, $\mathrm{df}=245, p<.01, \mathrm{x}^{2} / \mathrm{df}=2.07, \mathrm{GFI}=.87$, RMSEA $=.06, \mathrm{AGFI}=85, \mathrm{CFI}=.87, \mathrm{PGFI}=.71$ ) was shown. All value indicate the index overall acceptable.

〈Figure 2〉 Results of SEM Analysis

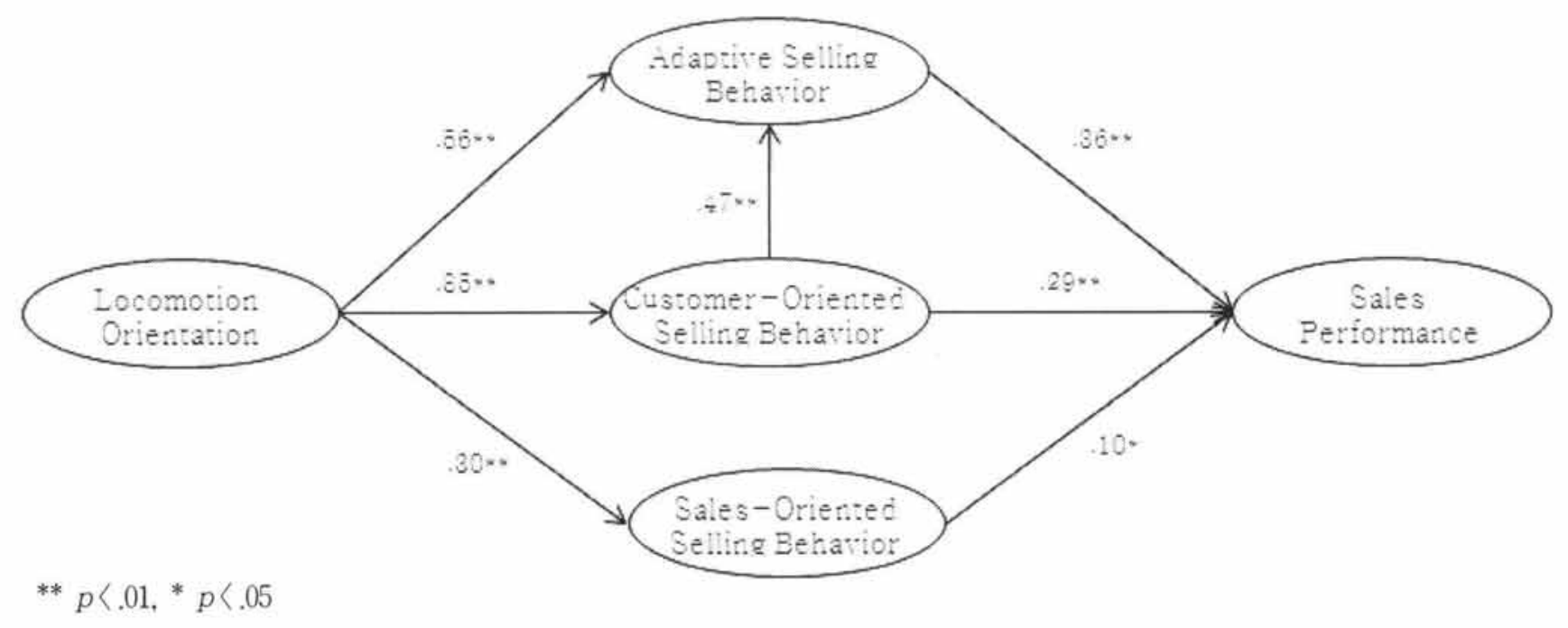

188 ASIA MARKETING JOURNAL Vol. 15 NN. 02 July 2013 


\subsection{Hypotheses Tests}

In this study, path analysis was used to test hypotheses. In hypothesis 1-1, locomotion orientation has a positive impact on adaptive selling behavior, and the hypothesis was sup$\operatorname{ported}(\beta=.56, p<.01)$. Hypothesis $1-2$, locomotion orientation on customer-oriented selling behavior in positive impact, and the hypothesis was $\operatorname{supported}(\beta=.85, p<.01)$. Hypothesis $1-3$. locomotion orientation on sales-oriented selling behavior in positive impact, the hypothesis was $\operatorname{supported}(\beta=.30, p<.01)$. These paths are significant at the level of .01, especially, the path between locomotion orientation and customeroriented selling behavior is very strong. The path of locomotion orientation to sales-oriented selling behavior is relatively weak. The reason why the path of locomotion orientation to customeroriented selling behavior is stronger than the path of locomotion orientation to adaptive selling behavior can be the inferences that adaptive selling behavior needs to interact with customers and needs to change behaviors during interaction.

In hypothesis 2, customer-oriented selling behavior has a positive effect on adaptive selling behavior, the hypothesis was $\operatorname{supported}(\beta=.47$, $p<.01$ ). Hypothesis $3-1$, adaptive selling behavior has a positive impact on sales performance, and hypothesis was $\operatorname{supported}(\beta=.36, p<$ .01 ). Hypothesis $3-2$, customer-oriented behavior has a positive impact on sales performance, and hypothesis was $\operatorname{supported}(\beta=.29, p<.01)$. Hypothesis 3-3, sales-oriented behavior has a positive impact on sales performance, and hypothesis was supported $(\beta=.10, p<.05)$.

Summary of hypotheses tests are as follows:

〈Table 3〉 Results of hypothesized path models

\begin{tabular}{|c|c|c|c|c|}
\hline Path & Hypothesis & $\begin{array}{c}\text { Standardized Regression } \\
\text { Weight }\end{array}$ & $p$ & Results \\
\hline $\mathrm{LO} \rightarrow \mathrm{ASB}$ & $\mathrm{H} 1-1(+)$ & .56 & .01 & supported \\
\hline $\mathrm{LO} \rightarrow \mathrm{CO}$ & $\mathrm{H} 1-2(+)$ & .85 & .01 & supported \\
\hline $\mathrm{LO} \rightarrow \mathrm{SO}$ & $\mathrm{H} 1-3(+)$ & .30 & .01 & supported \\
\hline $\mathrm{CO} \rightarrow \mathrm{ASB}$ & $\mathrm{H} 2(+)$ & .47 & .01 & supported \\
\hline $\mathrm{ASB} \rightarrow \mathrm{SP}$ & $\mathrm{H} 3-1(+)$ & .36 & .01 & supported \\
\hline $\mathrm{CO} \rightarrow \mathrm{SP}$ & $\mathrm{H} 3-2(+)$ & .29 & .01 & supported \\
\hline $\mathrm{SO} \rightarrow \mathrm{SP}$ & $\mathrm{H} 3-3(+)$ & .10 & .05 & supported \\
\hline
\end{tabular}

Note : $\mathrm{LO}=$ Locomotion Orientation, $\mathrm{ASB}=$ Adaptive Selling Behavior,

$\mathrm{CO}=$ Customer-oriented Selling Behavior, $\mathrm{SO}=$ Sales-oriented Selling Behavior, $\mathrm{SP}=$ Sales Performance 


\section{Conclusions}

\subsection{Summary}

The summary of this paper as follows:

First, in the effects of locomotion orientation on adaptive selling behavior, sales-oriented selling behavior, and customer-oriented selling behavior, all gave positive influences. Locomotion orientation affects salespeople' selling behavior as a motivation factor in action. No matter what type of selling behavior, sales performance will be presented. Secondly, the new path from customer-oriented selling behavior to adaptive selling behavior was found. This finding conflicts the results of existing studies.

This research conflicted with Franke and Park (2006) ' study, especially the path between adaptive selling behavior and customer-oriented selling behavior. Franke and Park(2006)'s study showed that the direction of the path between those selling behavior is from adaptive selling behavior to customer-oriented selling behavior. But results of this study showed that the direction is opposite, and so most researchers need to know these conflicting test results for concrete causality.

\subsection{Implications of Research}

This study with the theoretical implications is as follows. First, the motivational factor for selling behavior as a variable affecting salespeople's selling performance was recently revealed to the theoretical system of self-control theory. Sociopsychological approach to the motivational factor for this study was tried in previous studies, but it will be a motivational factor with the assumption that management style and focus on the elements around and meaningful contribution to the research because selling behavior had gained significant results. In other words, this study is the first attempt to investigate the path between locomotion orientation and adaptive selling behavior and SOCO. Secondly, there is an empirical conflict between our study and Franke and Park(2006)'s study. Franke and Park(2006)'s research showed that they tried to make empirical test of paths both from customer-oriented selling behavior to adaptive selling behavior and from adaptive selling behavior to customer-oriented selling behavior. Results in their meta analysis said that the one path, adaptive selling behavior to customer-oriented selling behavior, was statistically significant. The other path was not supported. Our study was contradictory to Franke and Park(2006)'s consequences. And so, figuring out clearly those causal paths remains.

This study with practical implications are as follows.

First of all, the salespeople' selling performance was affected by adaptive selling behavior, customer-oriented selling behavior, and salesoriented activities, such as the importance of 
selling behavior once again proven. It is necessary to enhance the capabilities that can be transformed into action appropriate to the needs of customers each sales step-by-step in the process of salespeople for various system through education and incentives, and to interact with customers and understand their customers relative to salespeople will. In order to enhance adaptive selling behavior, the company needs to do educational program and monitoring system with the positional promotion when salespeople get the high adaptive selling behavior. For example, a company can use a survey of customers who are satisfied or dissatisfied with salespeople' adaptive selling behavior. This helps to evaluate salespeople' selling behavior and make salespeople tense.

Secondly, the locomotion orientation of the salespeople is to cause this selling behavior. Management style to increase locomotion orientation is needed, which means, salespeople' superior about something should be conducted. In order to stimulate the selling behavior of the salespeople, most supervisors should use some managerial tools such as feedback, engagement, and rewards.

\subsection{Limitations and Future Research}

Limitations with this study are as follows.

First, the self-regulating tendency includes locomotion orientation and assessment orientation. In this study, because of the independence be- tween each other of the research model, authors did not study assessment orientation in our model. However, for the richness of theory, a study on the relationship between the two construct index to the frustration remains.

Secondly, the key variable of this study can be said that adaptive selling behavior variable is based on the continuity of business relationships between trading partners rounds of investigation in this study, causal relationship was estimated. Of course, based on the theory of procedural variable adjusted for the study design did not estimate the causal relationship, but it should be pointed out as a limitation of the study.

Future direction of related research is proposed as follows.

First, the limitations of this study also points out self regulatory mode of locomotion orientation and selling behavior affects how the relationship between assessment orientations there is a need to demonstrate. In this study, the study assumes independence between the two construct were in progress. There is a need to determine the causal relationship between each other.

Secondly, in a view of the need to increase the abundance of theoretical research, the future research should include locomotion orientation of the preceding factor aspect, organizational structure, organizational culture aspect, the relationship between a superior and subordinates, and incentive systems from a variety 
of perspectives.

〈Received March 23. 2013〉

〈Revised June 26. 2013〉

〈Accepted July 1. 2013〉

\section{References}

Avnet, Tamar and E. Tory Higgins(2003). "Locomotion, Assessment and Regulatory Fit: Value Transfer from 'How' to 'What,", Journal of Experimental Social Psychology, 39(5), 525-530.

Cravens, David W., Thomas N. Ingrm, Raymond W. LaForge, and Clifford E. Young(1993), "Behavior-based and Outcome-based Salesforce Control Systems," Journal of Marketing, 57(4), 47-59.

Franke, George R. and Jeong-Eun Park(2006), "Salesperson Adaptive Selling Behavior and Customer Orientation: A Meta-Analysis," Journal of Marketing Research, 43(4), 693-702.

Flaherty, Theresa B., Robert Dahlstrom and Steven J. Skinner(1999), “Organizational Values and Role Stress as Determinants of Customer-Oriented Selling Performance," Journal of Personal Selling and Sales Management, 19(2), 1-18.

Goff, Brent G., James S. Boles, Danny N. Bellenger, and Carrie Stojack(1997), “The Influence of Salesperson Selling Behaviors on Customer Satisfaction with Products," Journal of Retailing, 73(2), 171-183.

Guenzi, Paolo, Catherine Pardo, and Laurent Georges(2007), "Relational Selling Strategy and Key Account Managers' Relational Behavior: An Exploratory Study," Industrial Marketing Management, 36(1), 121133.

Gwinner, Kevin P., Mary Jo Bitner, Stephen W. Brown, and Ajith Kumar(2005), "Service Customization and Through Employee Adaptiveness," Journal of Service Research, 8 (2), 131-148.

Higgins, E. Tory and Arie W. Kruglanski(1995). A theory of regulatory modes: When $1^{-}$ comotion versus assessment is emphasized, Unpublished manuscript, Columbia University, New York.

Higgins, E. Tory, Arie W. Kruglansk, and Antonio Pierro(2003), “Regulatory Mode: Locomotion and Assessment as Distinct Orientation," In M. P. Zana(Ed.), Advances in Experimental Social Psychology, 35, 293-344, New York: Academic Press.

Homburg, Christian, Michael Müller, and Martin Klarmann(2011), "When Should the Customer Really Be King? On the Optimum Level of Salesperson Customer Orientation in Sales Encounters," Journal of Marketing, 75(3), 55-74.

Jasmand, Claudia, Vera Blazevic, and Ko de Ruyter(2012), "Generating Sales While Providing Service: A Study of Customer 
Service Representatives' Ambidextrous Behavior," Journal of Marketing. 76(1), 20-37.

Kim, Gwang-suk, Sang-tak Choi, and Janggwen Song(2009), “Adaptive Selling: A Marketing Strategy to Approach Each Segment According to Customer Orientation," Korean Management Review, 38(3), 669693.

Kruglanski, Arie W., Erik P. Thompson, E. Tory Higgins, M. Nadir Atash. Antonio Pierro, James Y. Shah, and Scott Spiegel (2000), "To 'Do the Right Thing' or to 'Just Do It': Locomotion and Assessment as Distinct Self-Regulatory Imperatives," Journal of Personality and Social Psychology, 79(5), 793-815.

Kruglanski, Arie W., Antonio Pierro, E. Tory Higgins, and Dora Capozza(2007), '”On the Move' or 'Staying Put': Locomotion, Need for Closure, and Reactions to Organizational Change," Journal of Applied Social Psychology, 37(6), 1305-1340.

Martin. Craig A. and Alan J. Bush(2006). "Psychological Climate. Empowerment, Leadership Style, and Customer-Oriented Selling: An Analysis of the Sales ManagerSalesperson Dyad," Journal of the Academy of Marketing Science, 34(3), 419-438.

Nunnally, Jim C.(1978), Psychometric Theory, 2nd ed., New York: McGraw-Hill Book Company.

Oliver, Richard L., and Erin Anderson(1994), "An Empirical Test of the Consequences of Behavior-and Outcome-Based Sales Control Systems," Journal of Marketing, 58(4), 53-67.

Park, Jeong-Eun and George D. Deitz(2006), "The Effect of Working Relationship Quality Salesperson Performance and Job Satisfaction: Adaptive Selling Behavior in Korean Automobile Sales Representatives," Journal of Business Research, 59(2), 204-213.

Pierro, Antonio, Arie W. Kruglanski, and E. Tory Higgins(2006), "Regulatory Mode and the Joys of Doing: Effects of 'Locomotion' and 'Assessment' on Intrinsic and Extrinsic Task-Motivation," European Journal of Personality, 20(5), 355-375.

Podsakoff, Philip M., Scott B. MacKenzie, Jeong-Yeon Lee and Nathan P. Podsakoff (2003). "Common Method Biases in Behavioral research: A Critical Review of the Literature and Recommended Remedies," Journal of Applied Psychology, 88(5), 879903.

Roman, Sergio and Dawn lacobucci(2010), "Antecedents and Consequences of Adaptive Selling Confidence and Behavior: A Dyadic Analysis of Salespeople and Their Customers," Journal of the Academy of Marketing Science, 38(3), 363-382.

Saxe, Robert and Barton A. Weitz(1982), "A Measure of the Customer Orientation of Salespeople," Journal of Marketing Research, 19(3), 343-351.

Schwepker, Charles H.(2003), "Customer-Oriented 
Selling: A Review, Extensions, and Directions for Future Research," Journal of Personal Selling and Sales Management, 23(2), 151-171.

Siguaw, Judy Ann Judice(1991), “The Relationship of Customer Orientation, Adaptive Selling and Selected Antecedents: A Causal Model," doctoral dissertation, College of Administration and Business, Louisiana Tech University.

Spiro, Rosann L. and Barton A. Weitz(1990), "Adaptive Selling: Conceptualization, Measurement, and Nomological Validity," Journal of Marketing Research, 27(1), 61-69.

Sujan, Harish, Barton A. Weitz, and Nirmalya Kumar(1994), "Learning Orientation, Working Smart, and Effective Selling," Journal of Marketing, 58(3), 39-52.

Sung, Hyung-Suk and Sang-Lin Han(2010), "Self-Regulatory Mode Effects on Emotion and Customer's Response in Failed ServicesFocusing on the Moderate Effect of Attribution Processing," Asia Marketing Journal, 12(2), 83-110.
Wachner, Trent, Christopher R. Plouffe, and Yany Gregorie(2008), “SOCO's Impact on Individual Sales Performance: The Integration of Selling Skills as a Missing Link," Industrial Marketing Management, 38(1), 32-44.

Walker, Orville C. Jr., Gilbert A. Churchill, Jr., and Neil M. Ford(1977), "Motivation and Performance in Industrial Selling: Present Knowledge and Needed Research," Journal of Marketing Research, 14(2), 156-168.

Weitz, Barton A., Harish Sujan, and Mita Sujan (1986), "Knowledge, Motivation, and Adaptive Behavior: A Framework for Improving Selling Effectiveness," Journal of Marketing, 50(4), 174-191.

Yoo, Changjo, Donggi Youn, and Junsang Yeo (2008), "A Structural Model of Salesperson Characteristics, Sales Behavior, and Sales Performance: Extension of Prior Model," Journal of Korean Marketing Association, 23(1), 1-21. 